\title{
Fast versus Turbulent Fluidization of Geldart Group B particles
}

\author{
Jia Wei Chew ${ }^{1}$ and Ray Cocco ${ }^{2}$ \\ ${ }^{1}$ Nanyang Technological University \\ ${ }^{2}$ Affiliation not available
}

July 21, 2020

\begin{abstract}
Both fast and turbulent fluidized beds exhibit entrainment, but the differences in the flow phenomena are not well understood. This study targeted a comparative analysis of the cluster (or streamer), mass flux, and segregation datasets from these two fluidization regimes. The particle systems were narrow particle size distributions (PSDs), binary mixtures, or broad PSDs of Geldart Group B particles. Relative to the fast fluidized bed, the turbulent bed exhibited (i) higher cluster probability and frequency, but lower cluster duration; (ii) lower local mass flux; and (iii) similar segregation extents. Regarding clusters, the relative dominance of the variables on probability was similar for both regimes, but there was a difference for probability and frequency. For overall mass flux, particle-related properties were more dominant with the turbulent bed. As for segregation, the radial position was the most influential in the fast fluidized bed, but the least in the turbulent one.
\end{abstract}

\section{Keywords}

Fluidization regime; Cluster; Mass Flux; Segregation; Machine learning; Random forest

\section{Introduction}

The fluidization regimes are well-acknowledged to be demarcated based mainly on superficial gas velocities, with the transition between the regimes characterized by various transition velocities ${ }^{1-5}$. On one hand, unique features exist in each regime, like presence or lack of bubbles and/or entrainment. On the other hand, overlapping features are well-known across different regimes, like the segregation of particles of different sizes and/or densities.

For dense-phase fluidization, the regimes, in order of increasing gas velocity, are particulate or homogenous fluidization, bubbling fluidization, and turbulent fluidization ${ }^{2}$. The particulate fluidization regime lacks bubbles and is limited to Geldart Group A particles. In contrast, the bubbling regime has approximately well-defined bubbles, and exist for both Geldart Groups A and B. The turbulent fluidization regime is noted for the formation of chaotic voids or less well-formed bubbles. Many studies have been performed to reveal the similarities and differences between the various dense-phase fluidization regimes. Bubbles exist in both the bubbling and turbulent regimes, but bubble breakup is a lot more dominant than bubble coalescence in the latter, leading to smaller, less well-defined bubbles that give much smaller pressure fluctuations ${ }^{6,7}$. It has been reported that, in the transition from bubbling to turbulent fluidization, more gas passed through the bed as bubbles for the Geldart Group B sand particles, but the flow of gas through the bed as bubbles did not increase for the Geldart Group A FCC (fluid cracking catalyst) particles ${ }^{8}$. With respect to lean-phase fluidization, the two regimes from high to lower particle concentration are referred to as fast fluidization and dilute transport ${ }^{9}$. As with dense-phase fluidization, these two regimes are distinguishable. Fast fluidization tends to have more of a core-annulus structure, whereas dilute transport can have none. Furthermore, fast fluidization can have significant back-mixing, whereas dilute transport has little. 
The regimes of interest in this study are the two right at the boundary of dense- and lean-phase fluidization, namely, the turbulent and fast fluidized beds. Regarding the turbulent fluidization regime, it marks the onset of entrainment ${ }^{1}$, and the bed surface becomes less distinguishable ${ }^{2}$. It is common in industrial fluidization because of advantages including vigorous gas-solid contact, favorable bed-to-surface heat transfer, high solid hold-up (typically $25-35 \%$ by volume), and limited axial gas mixing ${ }^{7}$. The fast fluidization regime is operated as a circulating fluidized bed due to the much higher entrainment rates ${ }^{9}$. In contrast to the turbulent fluidized bed in which only the gas flow is controlled, both the gas and solid flows are controlled in the fast fluidized bed. In both regimes, a denser region exists at the bottom and a more dilute region at the top, leading some studies to define the transition velocity between the two regimes based on the axial voidage profiles ${ }^{5}$.

Some studies have investigated the differences across the dense- and lean-phase fluidization regimes. The power spectral densities derived from pressure fluctuations indicated that bubble formation, eruption and coalescence contributed to the pressure fluctuation signal for particulate and bubbling fluidization, whereas clusters contributed to the signal response for turbulent fluidization and higher-velocity regimes ${ }^{10}$. Furthermore, the standard deviations of local voidage fluctuations were observed to be much lower in a high-density circulating fluidized bed riser relative to the bubbling and turbulent flow regimes, while the radial profiles of chaotic parameters were flatter in the bubbling and turbulent flow regimes than in dense suspension upflow

11. For particles of a wide particle size distribution (PSD), the reactor efficiency in the turbulent and fast fluidization regimes was higher than in the bubbling fluidization regime ${ }^{12}$. In both the turbulent and fast fluidization regimes, cluster sizes were observed to decrease with increasing velocity ${ }^{13}$. All these studies have provided beneficial insights into the different fluidization regimes. What remained amiss was a direct comparison of various fluidization phenomena between the turbulent and fast fluidized beds, which motivated the current study.

Therefore, this study targeted a detailed comparative analysis of the cluster (or streamer), flux and segregation phenomena between the fast and turbulent fluidized beds. The particle systems were either narrow PSDs, binary mixtures, or broad PSDs of Geldart Group B particles. Random forest analysis was employed to evaluate the relative influence of the variables on the phenomena assessed.

\section{Datasets}

Comprehensive datasets have been obtained in both a fast fluidized bed ${ }^{14-19}$ and a turbulent fluidized bed $^{20,21}$. The schematic diagrams of the experimental setups are displayed in Figure 1 . The fast fluidized riser had an inner diameter of $0.30 \mathrm{~m}$ and was $18.3 \mathrm{~m}$ tall, and had a mixing pot at the bottom and a rounded elbow exit at the top. The turbulent riser had an inner diameter of $0.184 \mathrm{~m}$ and was $4 \mathrm{~m}$ tall, and had a sintered stainless steel porous plate at the bottom and a blind tee exit at the top. Recirculation of the solid particles back to the riser was enabled via a pair of cyclones in series for the fast fluidized bed, and a single cyclone for the turbulent fluidized bed. 


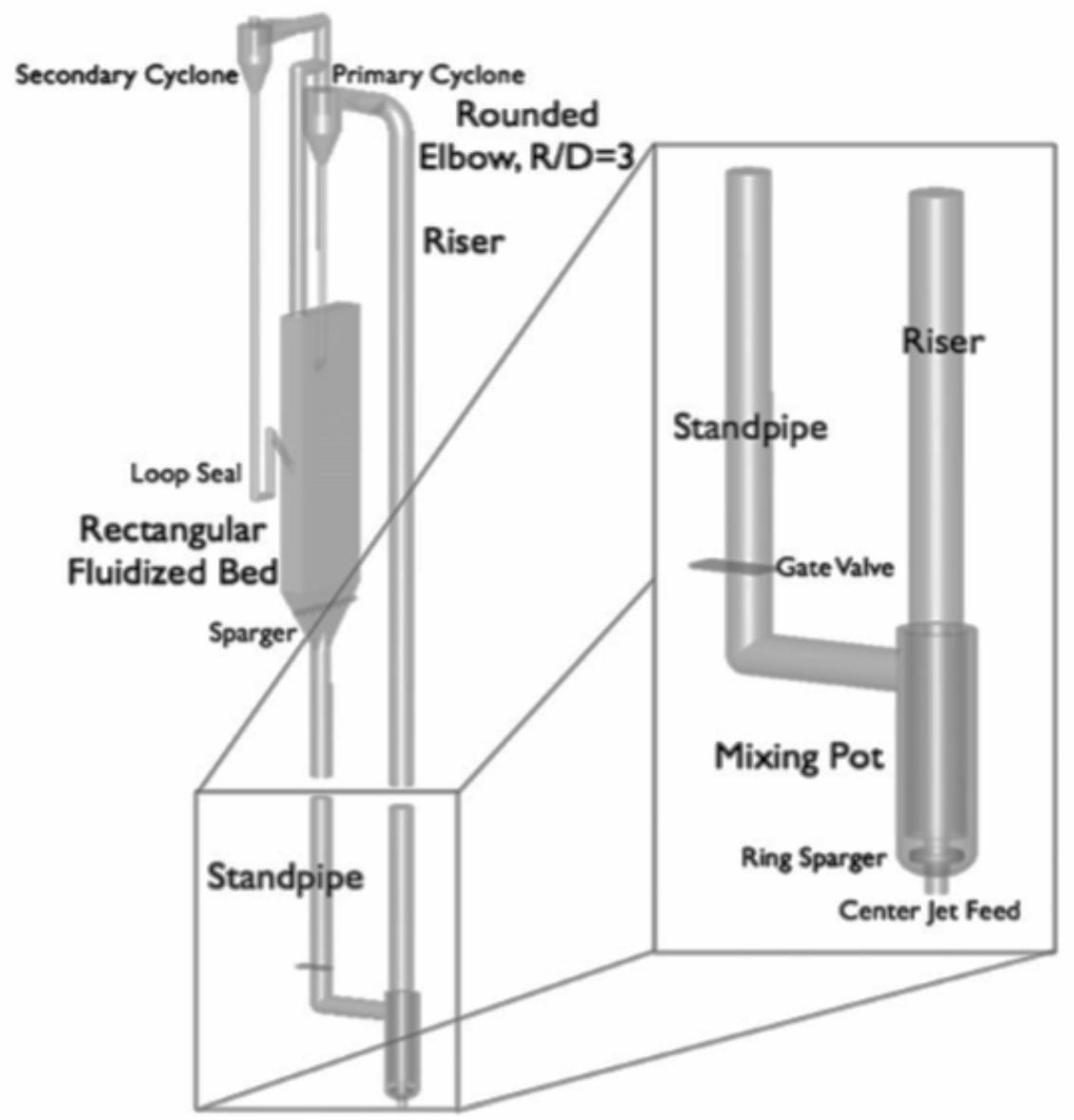

Fig. 1. Schematic diagram of CFB at PSRI. 


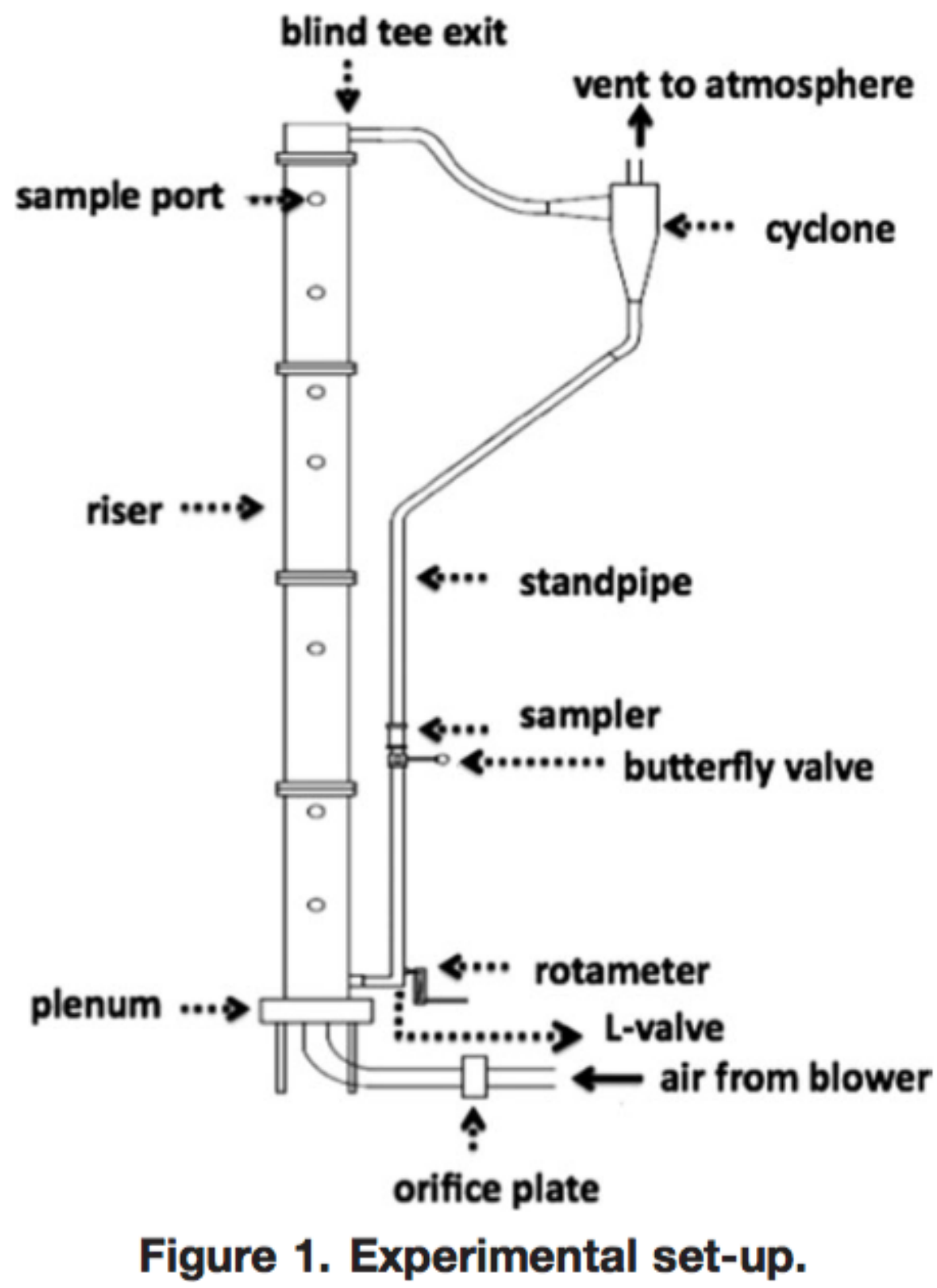

Figure 1. Experimental setups of the fast (left) and turbulent (right) fluidized beds. The fast fluidized riser had an inner diameter of $0.30 \mathrm{~m}$ and was $18.3 \mathrm{~m}$ tall, while the turbulent riser had an inner an inner diameter of $0.184 \mathrm{~m}$ and was $4 \mathrm{~m}$ tall. The fast fluidized bed schematic is reprinted from ${ }^{17}$, Copyright 2012, with permission from Elsevier. The turbulent fluidized bed schematic is reprinted from ${ }^{21}$, Copyright 2012, with permission from Elsevier.

The Geldart Group B particles evaluated are listed in Table 1. The particle types included glass, high-density polyethylene (HDPE), polystyrene and sand, with the average diameters $\left(d_{\text {ave }}\right)$ ranged between $165-650$ $\mu \mathrm{m}$ and densities $\left(\rho_{\pi}\right)$ between $900-2650 \mathrm{~kg} / \mathrm{m}^{3}$. The broad particle size distributions (PSDs), with larger standard deviations $\left(\sigma / d_{\text {ave }}\right)$, were particles used as received from the vendor. The other particles were pre-sieved to obtain narrower PSDs between two available sieves, which were either used as is (i.e., narrow PSDs) or mixed to form binary mixtures. 
Also listed in Table 1 are the operating conditions. The superficial gas velocities $\left(U_{g}\right)$ used in the fast fluidized bed were in the range of $10-17 \mathrm{~m} / \mathrm{s}$, which are an order of magnitude greater than that in the turbulent fluidized bed of 1.5 and $1.7 \mathrm{~m} / \mathrm{s}$. While the overall solid fluxes $\left(G_{s}\right)$ were controlled through a slide valve in the fast fluidized bed to range between $50-300 \mathrm{~kg} / \mathrm{m}^{2} / \mathrm{s}$, that in the turbulent bed depended on the superficial gas velocity $\left(U_{g}\right)$ and ranged between $0.05-0.51 \mathrm{~kg} / \mathrm{m}^{2} / \mathrm{s}$.

Table 1. Geldart Group B materials and operating conditions for the fast ${ }^{14-19}$ and turbulent ${ }^{20,21}$ fluidized beds.

\begin{tabular}{|c|c|c|c|c|c|c|}
\hline Regime & Material & $d_{\text {ave }}(\mu \mu)$ & $\rho_{S}\left(\mathrm{~kg} / \mathbf{m}^{3}\right)$ & $\sigma / \boldsymbol{d}_{\text {ave }}(\boldsymbol{\%})$ & $U_{g}(\mathbf{m} / \mathbf{s})$ & $\begin{array}{l}G_{s} \\
\left(\mathrm{~kg} / \mathrm{m}^{2} / \mathrm{s}\right)\end{array}$ \\
\hline \multirow[t]{12}{*}{ Fast } & Narrow & Narrow & Narrow & Narrow & Narrow & Narrow \\
\hline & PSD & PSD & PSD & PSD & PSD & PSD \\
\hline & Large glass & 650 & 2500 & 9 & $13.5 ; 17$ & $120 ; 260$ \\
\hline & Small glass & 170 & 2500 & 12 & $13.5 ; 17$ & $120 ; 260$ \\
\hline & Large HDPE & 650 & 900 & 11 & $13.5 ; 17$ & $120 ; 260$ \\
\hline & Binary & Binary & Binary & Binary & Binary & Binary \\
\hline & Mixture & Mixture & Mixture & Mixture & Mixture & Mixture \\
\hline & $\begin{array}{l}\text { Binary-size } \\
(50 \% \text { Large } \\
\text { glass + 50\% } \\
\text { Small glass) }\end{array}$ & $170 ; 650$ & 2500 & $9 ; 12$ & $13.5 ; 17$ & $120 ; 260$ \\
\hline & $\begin{array}{l}\text { Binary-density } \\
(50 \% \text { Large } \\
\text { glass + } 50 \% \\
\text { Large HDPE) }\end{array}$ & 650 & $2500 ; 900$ & $9 ; 11$ & $13.5 ; 17$ & $120 ; 260$ \\
\hline & Broad & Broad & Broad & Broad & Broad & Broad \\
\hline & PSD & PSD & PSD & PSD & PSD & PSD \\
\hline & Glass & 170 & 2500 & 25 & $10 ; 15$ & $50 ; 300$ \\
\hline \multirow[t]{11}{*}{ Turbulent } & Narrow & Narrow & Narrow & Narrow & Narrow & Narrow \\
\hline & PSD & PSD & PSD & PSD & PSD & PSD \\
\hline & Glass & 165 & 2500 & 5 & 1.5 & 0.37 \\
\hline & Polystyrene & 327.5 & 1050 & 5 & 1.5 & 0.05 \\
\hline & Sand & 196 & 2650 & 5 & 1.7 & 0.19 \\
\hline & Binary & Binary & Binary & Binary & Binary & Binary \\
\hline & Mixture & Mixture & Mixture & Mixture & Mixture & Mixture \\
\hline & $\begin{array}{l}\text { Glass- } \\
\text { Polystyrene } \\
(25 \%, 50 \%, \\
75 \%)\end{array}$ & $165 ; 327.5$ & $2500 ; 1050$ & $5 ; 5$ & 1.5 & $0.16-0.30$ \\
\hline & Broad & Broad & Broad & Broad & Broad & Broad \\
\hline & PSD & PSD & PSD & PSD & PSD & PSD \\
\hline & Sand & 195 & 2650 & $\begin{array}{l}5,10,25,40 \\
65\end{array}$ & 1.7 & $0.19-0.51$ \\
\hline
\end{tabular}

For both the fast and turbulent fluidized beds, local measurements were taken at 11 radial positions and 5 heights along the riser for each particle system and operating condition. The riser phenomena assessed here include cluster (namely, local appearance probability, duration, and frequency) ${ }^{16,17,20}$, mass flux (both local flux and overall flux across the cross-section) ${ }^{15,21}$ and segregation ${ }^{14,21}$. The same instruments fabricated by PSRI were used for characterization. Specifically, the local clusters were measured using fiber optic probes, which housed two fibers that converged at the probe tip, while the local mass fluxes were measured using 
extraction probes with an inner diameter of $0.017 \mathrm{~m}$ and the probe tip oriented $90^{\circ}$ to the probe shaft to capture upward or downward flow. The samples collected from the extraction probes were sieved to obtain segregation data.

\section{Analysis Method}

The Random Forest (RF) method ${ }^{22}$ was adopted to determine the relative importance of each variable on cluster, flux, and segregation characteristics. The scaling of variables was not needed.

The self-organizing map (SOM) was also adopted to ascertain the influence of the variables or lack thereof. $\mathrm{SOM}$ is useful in reducing multi-dimensional data to two-dimensional representations to ease the interpretation of large datasets ${ }^{23,24}$. The datasets were scaled to the same bounds between -0.5 and $0.5^{25}$ before SOM was carried out:

$x_{\text {scaled }}=\frac{x-x_{\min }}{x_{\max }-x_{\min }}-0.5(1)$

where $x, x_{\min }$ and $x_{\max }$ are respectively the value of the data point considered, the minimum value of the variable, and the maximum value of the variable.

The two-sample t-test was used to evaluate if there is any significant difference between the datasets from the fast and the turbulent beds, without assuming that the populations have equal variances. The test statistic was calculated by:

$t=\frac{x-y}{\sqrt{\frac{s_{x}^{2}}{n_{x}}+\frac{s_{y}^{2}}{n y}}}(2)$

where $x$ and $y$ are the sample means, $s_{x}$ and $s_{y}$ are the sample standard deviations, and $n_{x}$ and $n_{y}$ are the sample sizes. The null hypothesis that the two datasets are from populations with means that are not different was tested at the $95 \%$ confidence level.

All analyses were performed with Matlab R2016b.

\section{Results and Discussion}

\section{Cluster}

Figure 2 displays the boxplots of the local cluster data, specifically 1188 datasets from the fast fluidized bed ${ }^{16,17}$ and 378 datasets from the turbulent one ${ }^{20}$. The fiber optic probe was used for cluster detection, with each measurement lasting $30 \mathrm{~s}$ and cluster identification enabled using wavelet decomposition. Cluster probability is the fraction of time instances whereby cluster is detected, and is bounded between 0 and 1 , while cluster duration and cluster frequency reflects respectively cluster size and number of clusters per unit time. Using a two-sample t-test, the null hypotheses were rejected for all three characteristics, indicating the data from the fast and turbulent fluidized beds were from populations with different means within the $95 \%$ confidence level. Relative to the fast fluidized bed, the turbulent bed with $U_{g}$ values of an order-of-magnitude lower gave higher cluster probability, lower duration, and much higher frequency. In particular, the higher cluster probability for the turbulent bed was tied to the significantly higher number of clusters (i.e., cluster frequency). The lower cluster probability and frequency in the fast fluidization regime are tied to lower bed densities than the turbulent bed, since by definition the former is classified under lean-phase fluidization while the latter dense-phase fluidization ${ }^{1,2,9}$. The higher cluster duration in fast fluidization is presumed to be due to the less chaotic hydrodynamics relative to the turbulent bed, because the latter is dominated by bubble break-up ${ }^{2}$ and is known to exhibit higher standard deviations of local voidage fluctuations ${ }^{11}$. Another study postulated that cluster sizes adjust to balance the gas drag force and gravity, thus smaller clusters were observed to exist in the turbulent bed compared to the fast one ${ }^{13}$, which agrees with the comparison here.

\section{Hosted file}


image3.emf available at https://authorea.com/users/344990/articles/471345-fast-versusturbulent-fluidization-of-geldart-group-b-particles

Figure 2. Box plots of local cluster characteristics. The left column corresponds to 1188 datasets from a fast fluidized bed ${ }^{16,17}$, while the right column corresponds to 378 datasets from a turbulent fluidized bed ${ }^{20}$.

To understand the relative influence of the various variables, Figure 3 displays the random forest analysis results. The variables include particle properties (namely, $d_{a v e}$ and $\rho_{\pi}$ ), riser position (namely, radial position normalized with respect to the riser radius $(r / R)$, and axial position normalized with respect to the riser height $(h / H)$ ) and operating condition (namely, $U_{g}$ and $G_{s}$ ). Regarding cluster probability, the similarity between the fast and turbulent fluidized beds lies in $h / H$ being the most dominant and $U_{g}$ being least dominant in both fluidization regimes. For the cluster duration and frequency, the relative influences were different for the two fluidized beds. For the fast fluidized bed, four of the six variables (namely, $d_{\text {ave }}, \rho_{\pi}$ ,$r / R$, and $\left.G_{s}\right)$ were approximately similar in influencing cluster duration, while $d_{\text {ave }}$ was the most influential on cluster frequency. The lack of a more distinctively dominant variable among the six evaluated here is because the single most influential factor has been reported earlier to be whether the particle system was monodisperse or not (Figure 4) ${ }^{26}$.

As for cluster duration and frequency in the turbulent fluidized bed, $h / H$ was by far the most dominant, which is tied to the steep particle concentration drop with height typical of this regime ${ }^{2}$, while $r / R$ was the least important, which is consistent with the relatively flat radial profiles of chaotic parameters reported earlier ${ }^{11}$. The different variables governing the cluster duration and frequency suggest that the underlying mechanisms leading to cluster formation were different in the different regimes.

\section{Hosted file}

image4.emf available at https://authorea.com/users/344990/articles/471345-fast-versusturbulent-fluidization-of-geldart-group-b-particles

Figure 3. Random Forest out-of-bag permuted predictor importance estimates for local cluster characteristics. The left column corresponds to 1188 datasets from a fast fluidized bed ${ }^{16,17,25}$, while the right column corresponds to 378 datasets from a turbulent fluidized bed ${ }^{20}$.

In an earlier study ${ }^{26}$, the 1188 cluster datasets in the fast fluidized bed were found to be classifiable into two distinct data assemblies, with one composed of monodisperse particle systems (i.e., three narrow PSDs) and the other of non-monodisperse particle systems (i.e., two binary mixtures and one broad PSD), as shown in the cluster frequency versus duration plot in Figure 4. Clearly, the clusters from turbulent fluidization appear to be markedly different from that of fast fluidization, particularly in terms of much higher cluster frequency. Although the turbulent datasets consist of both monodisperse and non-monodisperse particle systems, the data points only overlap with the monodisperse data points of the fast fluidized bed. A closer look was taken at the data collected from turbulent fluidization to investigate if the data can be classified into distinct data assemblies based on the monodispersity versus non-monodispersity of the particle system, per that observed for fast fluidization (Figure 4). Figure 5 shows the plots of cluster frequency versus duration, with the data for the different particle systems represented by different symbols. Using different colors to represent all nine different particle systems, Figure 5a indicates no obvious demarcation into distinct data assemblies. Using three colors to represent the three particle systems (namely, narrow PSDs, binary mixtures, and broad PSDs), Figure 5b shows that, relative to the narrow PSDs, the maximum frequency of the binary mixtures was approximately half of that of the narrow PSDs or broad PSDs. Figure $5 \mathrm{c}$ presents data for the binary mixtures and the two constituents of narrow PSDs. Although the narrow PSD of polystyrene (PS) particles gave high-frequency clusters, the binary mixtures did not exhibit these, but instead gave clusters with larger durations than that of either constituent. As for the broad PSD mixtures, Figure 5d shows that the cluster frequencies were largely similar to that exhibited by the narrow PSD, and a few clusters had durations greater than that of the narrow PSD. Therefore, whereas the presence of particle mixtures (either binary mixtures or broader PSDs) gave significantly lower cluster durations in the fast fluidized bed (Figure 4), the effect is less marked in the turbulent fluidized bed (Figure 5). This again affirms that the underlying 
mechanisms governing cluster formation are different in the different regimes.

\section{Hosted file}

image5.emf available at https://authorea.com/users/344990/articles/471345-fast-versusturbulent-fluidization-of-geldart-group-b-particles

Figure 4. Cluster frequency versus duration. 1566 datasets, with 378 from the turbulent fluidization regime and 1188 from the fast fluidization regime.

\section{Hosted file}

image6.emf available at https://authorea.com/users/344990/articles/471345-fast-versusturbulent-fluidization-of-geldart-group-b-particles

Figure 5. Cluster frequency versus duration for the turbulent fluidization regime: (a) all 378 datasets; (b) all 378 datasets, represented by three colors reflecting three particle systems (namely, narrow PSDs, binary mixtures, broad PSDs); (c) 210 datasets of binary mixtures and narrow PSD constituents; and (d) 168 datasets of broad PSD mixtures and the narrow PSD constituent.

\section{Mass Flux}

Using the extraction probe, both the upward and downward local mass flux at each radial position was measured over 20 to $30 \mathrm{~s}$. The overall mass flux at each axial position was calculated as the net mass flux integrated across the riser cross-section ${ }^{15,21}$ :

$G_{s}=\sum_{r=1}^{\text {total radial positions }}\left[\left(G_{r, \text { upward }}-G_{r, \text { downward }}\right) \times A_{r}\right](3)$

where $G_{r}$ is the measured local mass flux at radial position $r$, and $A_{r}$ is the annular area corresponding to each $r$. The local mass flux was normalized with respect to the overall mass flux for a fairer comparison in view of experimental variations of $\pm 10 \%$ in $G_{s}{ }^{15,21}$ :

$G_{r, \text { net }, \text { norm }}=\frac{G_{r, \text { upward }}-G_{r, \text { downward }}}{G_{s}}(4)$

Figure 6 presents the boxplots of the overall and local mass flux data, specifically 1320 datasets from the fast fluidized bed ${ }^{15}$ and 255 datasets from the turbulent one ${ }^{21}$. Clearly, the overall flux $\left(G_{s}\right)$ in the fast fluidized bed was a few orders of magnitude greater than that in the turbulent fluidized bed. It should be noted that the overall flux in the fast fluidized bed was controlled to meet targeted values by a slide valve that controls the amount of particles entering the riser, whereas that in the turbulent fluidized bed depended on the targeted superficial gas velocity $\left(U_{g}\right)$. As for the normalized local flux $\left(G_{r, n e t, n o r m}\right)$, using the two-sample t-test, the null hypothesis was rejected, indicating the data from the fast and turbulent fluidized beds had different means at the $95 \%$ confidence level. Although the median values were of the same order of magnitude for both beds, the spread of values was a lot greater for the turbulent bed relative to the fast bed, suggesting greater radial and axial variations of local flux in the former.

\section{Hosted file}

image7.emf available at https://authorea.com/users/344990/articles/471345-fast-versusturbulent-fluidization-of-geldart-group-b-particles

Figure 6. Box plots of local and overall flux. For local flux, the fast fluidized bed had 1320 datasets $^{15}$, while the turbulent fluidized bed had 255 datasets ${ }^{21}$. For overall flux, the fast fluidized bed had 1320 datasets ${ }^{15}$, while the turbulent fluidized bed had 378 datasets ${ }^{21}$.

To understand the relative influence of the variables on overall and local flux, Figure 7 displays the results from the random forest analysis. For overall flux, the variables were negatively and positively correlated in the cases of fast and turbulent beds, respectively. Two further notes on this are highlighted. Firstly, it should be noted that the magnitude of the estimates for overall flux in fast fluidization was approximately half that in turbulent fluidization, which is because the most dominant influence by far in the former has 
been identified to be the pressure at the bottom of the riser ${ }^{27}$. Secondly, the positive relationship between overall flux and particle properties (namely, $d_{a v e}$ and $\rho_{\pi}$ ) in turbulent fluidization is expected, since the overall flux has been linked to the collisional momentum transfer effects earlier ${ }^{20}$. Specifically, it was shown for the binary mixture of narrow PSDs of glass (referred to as 'fine' due to the lower terminal velocity) and PS (referred to as 'coarse' due to the lower terminal velocity) that the overall flux increased then decreased with the percentage mass of the fines (i.e., the glass species), and the non-monotonic behavior was tied to a trade-off in which collisional momentum transfer from fine to coarse particles dominated at lower fine contents and a decreasing amount of coarse particles dominated at high fine content. In contrast to overall flux, the relative influences for local flux were similar between the fast and turbulent beds for local flux. With respect to local flux, $r / R$ was the most dominant, followed by $h / H$, implying the importance of position within the riser relative to other variables. The radial dependence is expected for the fast fluidized bed due to the well-acknowledged annulus flow behavior ${ }^{19,28,29}$, but surprising for the turbulent bed wherein core-annulus flow structures are not generally acknowledged to exist ${ }^{4}$. Notably, the turbulent fluidized bed data presented here has been shown to display more prominent radial variations of the local fluxes for some particle systems, namely, the narrower lognormal PSDs and pure polystyrene systems ${ }^{21}$, which suggests differences between the core and annulus flows. More studies are needed to ascertain this.

\section{Hosted file}

image8.emf available at https://authorea.com/users/344990/articles/471345-fast-versusturbulent-fluidization-of-geldart-group-b-particles

Figure 7. Random Forest out-of-bag permuted predictor importance estimates for local (left column) and overall (right column) mass flux. For local flux, the fast fluidized bed had 1320 datasets ${ }^{15}$, while the turbulent fluidized bed had 255 datasets ${ }^{21}$. For overall flux, the fast fluidized bed had 1320 datasets ${ }^{15}$, while the turbulent fluidized bed had 378 datasets ${ }^{21}$.

Entrainment correlations typically incorporate dimensionless numbers such as Reynolds (Re), Archimedes $(\mathrm{Ar})$ and Froude $(\mathrm{Fr})$, and also particle properties in terms of minimum fluidization velocity $\left(U_{m f}\right)$ and terminal velocity $\left(U_{t}\right)^{30}$. The equations to calculate these parameters (namely, particle $\operatorname{Re}\left(\mathrm{Re}_{\mathrm{p}}\right)$, relative $\operatorname{Re}\left(\operatorname{Re}_{\mathrm{i}}\right)$, terminal $\operatorname{Re}\left(\operatorname{Re}_{\mathrm{t}}\right), U_{t}, \mathrm{Ar}, U_{m f}$, and Fr) are presented in the Appendix.

Figure 8 shows the relative influence of the variables on the overall flux in the fast and turbulent fluidized beds. Comparing the two regimes, the relative influence of the variables were different. An earlier study has indicated that the pressure at the bottom of the riser $\left(P_{b o t}\right)$ was the most influential on overall flux in the fast fluidization regime, while other variables comparatively had a negligible influence ${ }^{27}$. The $P_{b o t}$ data was unfortunately not available for the turbulent dataset, so cannot be shown for comparison between the regimes. Nonetheless, it can be inferred from the approximately two-fold larger magnitudes of the estimates for the turbulent bed the relatively greater importance of particle properties, which implies that $P_{b o t}$ was not as dominant an influence.

In addition, Figure 9 shows the SOM weight planes, which are useful for ascertaining the dominance of the influence ${ }^{27}$, of the two most dominant influencers, the least dominant influencer and also the overall flux for each regime. Specifically, the shades reflect the weights, with lighter and darker representing larger and smaller weights, respectively. The more similar the color gradients are, the stronger the correlation of the variables is. Clearly, (i) the color distributions for overall flux of the fast fluidized bed are rather dissimilar even with the top two influences (top row) shown in Figure 8, indicating a less significant effect of particle-related properties on overall flux, since $P_{b o t}$ was an overly dominant influence ${ }^{27}$; and (ii) the color distributions for overall flux of the turbulent fluidized bed are much more similar to the top two influences (top row), indicating a more significant influence of these particle properties related parameters. The SOM weight planes of the least influence (bottom row) in each fluidization regime are also shown in Figure 9. For the fast regime, the patterns are dissimilar. For the turbulent regime, some similarity in patterns with the overall flux is evident, but lesser compared to the top influences. Thus, the SOM analysis further affirms the more significant influence of particle properties or its related parameters on the turbulent bed relative 
to the fast one. Interestingly, although the driver for the overall flux in the turbulent bed was $U_{g}$, it had the least influence as a standalone variable, which again emphasizes the importance of particle properties in affecting overall flux in the turbulent regime.

\section{Hosted file}

image9.emf available at https://authorea.com/users/344990/articles/471345-fast-versusturbulent-fluidization-of-geldart-group-b-particles

Figure 8. Random Forest out-of-bag permuted predictor importance estimates for overall mass flux for the fast fluidized bed ${ }^{15}$ and turbulent fluidized bed ${ }^{21} .1320$ and 378 datasets analyzed for fast and turbulent fluidization, respectively. The error bars represent two standard deviations of 10 repeats.

Fast

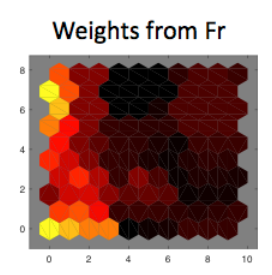

Weights from $\operatorname{Re}_{\mathrm{p}}$

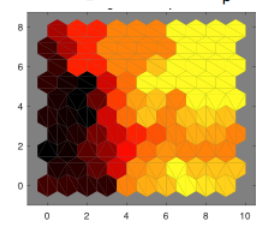

(1)
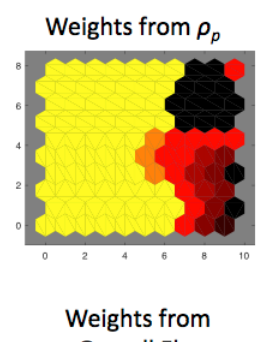

Overall Flux

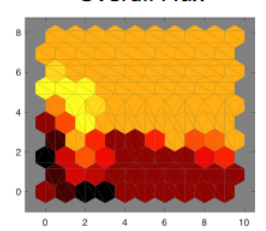

Turbulent
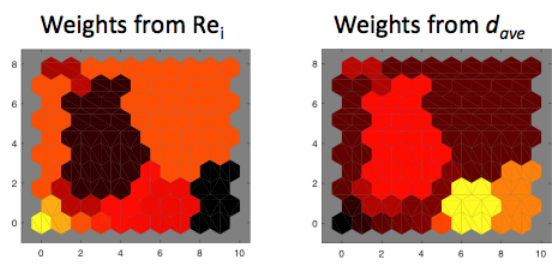

Weights from Overall Flux
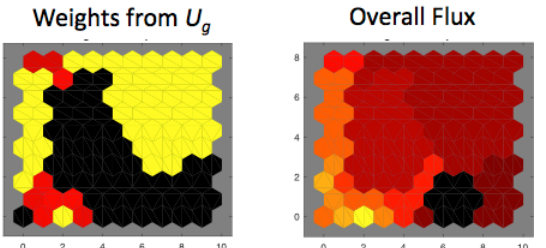

Figure 9. SOM weight planes (100 neurons) of three most dominant influences (top row) and two least influences (bottom row) on overall flux, as depicted in Figure 8, for the fast and turbulent fluidized beds. 1320 and 378 datasets analyzed for fast and turbulent fluidization, respectively.

\section{Segregation}

Figure 10 shows the boxplots of the segregation data (specifically, the percentage mass of the more massive species) for both the fast and turbulent fluidized beds. The particle mixtures were either binary mixtures or broad PSDs. Compared to the fast fluidized bed, the turbulent bed exhibited a greater spread of segregation extents. Interestingly, although the null hypotheses were rejected for cluster and flux characteristics, the null hypothesis cannot be rejected for the segregation datasets at the $95 \%$ confidence level, indicating that there is no significant difference between the means of the two populations. The similarity is surprising because segregation is driven by granular temperature ${ }^{31,32}$, whereby larger particles dissipate more than smaller particles, and it was expected that the dissipation would be more significant in the fast fluidized bed wherein collisional stress was greater.

\section{Hosted file}

image11.emf available at https://authorea.com/users/344990/articles/471345-fast-versusturbulent-fluidization-of-geldart-group-b-particles

Figure 10. Box plots of local segregation data in terms of percentage mass of the more massive species for binary mixtures and broad PSDs. The fast fluidized bed had 324 datasets ${ }^{14}$, while the turbulent fluidized bed had 190 datasets ${ }^{21}$.

Figure 11 presents the random forest analyses of the relative influence of the variables on segregation extents. While both axial and radial segregation are well acknowledged for risers ${ }^{14,21,33-36}$, two interesting observations 
are made with respect to the contrast between the fast and turbulent fluidized beds. Firstly, while $r / R$ was the most influential in the fast fluidized bed, it was the least in the turbulent bed. This is because the coreannulus profile is generally more significant in the fast fluidized bed relative to that in the turbulent one, and the radial profiles of chaotic parameters have been reported to be flatter for the turbulent bed ${ }^{11}$. Notably, this is in contrast to that for local mass flux (Figure 7), in which $r / R$ was the most dominant influence for both regimes. More studies are needed to understand why $r / R$ has such significant effect on the local mass flux but not segregation in the turbulent fluidization regime. Secondly, while $h / H$ had a negligible influence in the fast fluidized bed, it was more significant in the turbulent bed. This is to be expected as the particle concentration gradient is more significant than that of the fast fluidized bed. Therefore, although Figure 10 shows the two segregation datasets from the two fluidization regimes were statistically similar, Figure 11 suggests that different mechanisms govern the segregation behaviors.

\section{Hosted file}

image12.emf available at https://authorea.com/users/344990/articles/471345-fast-versusturbulent-fluidization-of-geldart-group-b-particles

Figure 11. Random Forest out-of-bag permuted predictor importance estimates for local segregation data in terms of percentage mass of the more massive species for binary mixtures and broad PSDs. The fast fluidized bed had 324 datasets $^{14}$, while the turbulent fluidized bed had 190 datasets $^{21}$.

While the mixture compositions were fixed in both the binary mixtures and broad PSDs for the fast fluidized bed, the percentage mass of the binary mixtures (namely, 25\%, $50 \%$ and $75 \%$ of fine, which refers to the narrow PSD glass) and also the widths of the broad PSDs $\left(\sigma / d_{a v e}=10 \%, 25 \%, 40 \%\right.$, and $\left.65 \%\right)$ were varied in the turbulent bed. Figure 12 shows the random forest analysis of the relative influence of the variables for the binary mixtures and broad PSDs. Although $r / R$ was the most influential in segregation in the fast fluidized bed (Figure 11) ${ }^{25}$, it had little influence on both non-monodisperse particle systems (i.e., binary mixtures and broad PSDs) in the turbulent bed (Figure 12). Figure 12 shows clearly that the relative influences for the two types of non-monodisperse mixtures were different, which agrees with earlier studies that also indicated different behaviors between binary mixtures and broad PSDs ${ }^{14,16,20,21,37-39}$. For binary mixtures, the composition of the constituents was approximately as important as the overall mass flux $\left(G_{s}\right.$ ) in influencing segregation. On the other hand, for the broad PSDs, $h / H$ was the most influential, followed by $\sigma / d_{\text {ave }}$ and $G_{s}$, which were equally influential. Interestingly, in both cases, the extent of polydispersity (specifically, represented by the percent fines for the binary mixtures and $\sigma / d_{\text {ave }}$ for the broad PSDs) and $G_{s}$ had similar influences on segregation.

\section{Hosted file}

image13.emf available at https://authorea.com/users/344990/articles/471345-fast-versusturbulent-fluidization-of-geldart-group-b-particles

Figure 12. Random Forest out-of-bag permuted predictor importance estimates for local segregation data in terms of percentage mass of the more massive species for binary mixtures (90 datasets) and broad PSDs $(100 \text { datasets })^{14}$.

\section{Conclusion}

To enhance the understanding of the difference between the fast and turbulent fluidization regimes, the cluster, mass flux, and segregation datasets of Geldart Group B particles were comparatively analyzed. While the fluidized beds were of different sizes, the measurement instruments used were the same, specifically, fiber optic probes for clusters, extraction probes for local mass flux and sieve for segregation. The particle systems investigated in both regimes included narrow PSDs, binary mixtures, and broad PSDs.

Regarding clusters, all three characteristics (namely, probability, duration, and frequency) were statistically different between the two regimes. Relative to the fast fluidized bed, the turbulent bed gave higher cluster probability and frequency due to higher bed density, and lower duration due to more chaotic hydrodynamics. 
For cluster probability, the relative dominance of the variables was similar for both fast and turbulent fluidized beds, with $h / H$ being most dominant and $U_{g}$ least. The mechanisms underlying cluster formation appeared to be different in the two regimes, because (i) the relative influences on cluster duration and frequency were different for the two fluidized beds; and (ii) although the monodisperse (i.e., narrow PSD) systems gave distinctly larger clusters than the non-monodisperse (i.e., binary mixtures and broad PSDs) ones in the fast fluidized bed, the different dispersity of the particle systems gave similar cluster durations in the turbulent bed.

Regarding local mass flux, the data from the fast and turbulent fluidized beds were statistically different, with the latter giving a lower median. Although the median values were of the same order of magnitude, the prevalence of downflow was much greater for the turbulent bed. While an earlier study has shown that particle-related properties had little influence on the overall mass flux in the fast fluidized bed, it was shown here that particle-related properties played a more significant role in the turbulent bed.

Regarding segregation, although the segregation extents were expected to be different in the two fluidization regime to the much greater dissipation and collisional stress in fast fluidization, the segregation datasets from the two fluidized beds were found to be statistically similar. Radial position $(r / R)$ was the most influential variable on segregation in the fast fluidized bed, but the least in the turbulent one, because of the more pronounced core-annulus profiles in the former. While $h / H$ had a negligible influence in the fast fluidized bed, it was more significant in the turbulent bed.

The comparative analysis of the two fluidization regimes here, therefore, provides more insights into the differences in flow phenomena. Further studies recommended include investigation of whether and under what circumstances does the core-annulus profile exist for the turbulent regime, and why radial position influences local mass flux but not segregation in the turbulent bed.

\section{Acknowledgement}

We acknowledge funding from the Singapore Ministry of Education Tier 1 Grant (2019-T1-002-065).

\section{Appendix}

Particle Reynolds number $\left(\operatorname{Re}_{p}\right)$ was calculated by:

$\operatorname{Re}_{p}=\frac{U_{g} d_{\text {ave }} \rho_{g}}{\mu}(\mathrm{A} 1)$

where $U_{g}$ is the superficial gas velocity, $d_{\text {ave }}$ is the average particle diameter, $\rho_{g}$ is the gas density and $\mu$ is the gas viscosity.

Relative Reynolds number $\left(\operatorname{Re}_{i}\right)$ was calculated by:

$\operatorname{Re}_{i}=\frac{\left(U_{g}-U_{t}\right) d_{\mathrm{ave}} \rho_{g}}{\mu}(\mathrm{A} 2)$

where $U_{t}$ is the terminal velocity of the particle.

Reynolds number based on terminal velocity $\left(\operatorname{Re}_{i}\right)$ was calculated by:

$\operatorname{Re}_{t}=\frac{U_{t} d_{\mathrm{ave}} \rho_{g}}{\mu}(\mathrm{A} 3)$

Terminal velocity $\left(U_{t}\right)$ was calculated by:

$U_{t}=\frac{U_{t}^{*}}{\left(\frac{\rho_{g}^{2}}{\mu\left(\rho_{p}-\rho_{g}\right) g}\right)^{\frac{1}{3}}}(\mathrm{~A} 4)$

where

$U_{t}^{*}=\left(\frac{18}{d_{\mathrm{ave}}^{*}}+\frac{2.335-1.744 \varphi}{d_{\mathrm{ave}}^{*} 0.5}\right)^{-1}($

where $\varphi$ is particle sphericity and $d_{\mathrm{ave}}^{*}$ was calculated by: 
$d_{\mathrm{ave}}^{*}=d_{\mathrm{ave}}\left(\rho_{g}\left(\rho_{p}-\rho_{g}\right) \frac{g}{\mu^{2}}\right)^{\frac{1}{3}}($

where $g$ is gravitational acceleration.

Archimedes number (Ar) was calculated by:

$\mathrm{Ar}=\frac{g d_{\mathrm{ave}}^{3} \rho_{g}\left(\rho_{p}-\rho_{g}\right)}{\mu^{2}}(\mathrm{~A} 7)$

Minimum fluidization velocity $\left(U_{\mathrm{mf}}\right)$ was calculated by:

$K_{1} \operatorname{Re}_{p, m f}^{2}+K_{2} \operatorname{Re}_{p, m f}=\operatorname{Ar}(\mathrm{A} 8)$

where $\operatorname{Re}_{p, m f}$ is the particle Reynolds number when $U_{g}=U_{\mathrm{mf}}$, and $K_{1}$ and $K_{2}$ were calculated by:

$K_{1}=\frac{1.75}{\varepsilon_{\mathrm{mf}}^{3} \varphi}(\mathrm{A} 9) K_{2}=\frac{150\left(1-\varepsilon_{\mathrm{mf}}\right)}{\varepsilon_{\mathrm{mf}}^{3} \varphi^{2}}(\mathrm{~A} 10)$

where $\varepsilon_{\mathrm{mf}}$ is volumetric bed voidage when $U_{g}=U_{\mathrm{mf}}$.

The Froude number (Fr) was calculated by:

$\operatorname{Fr}=\frac{\left(U_{g}-U_{t}\right)^{2}}{g d_{\text {ave }}}(\mathrm{A} 11)$

\section{References}

1. Kunii D, Levenspiel O. Fluidization engineering (Chapter 1: Introduction). Butterworth-Heinemann series in chemical engineering . 2nd ed. Boston: Butterworth-Heinemann,; 1991.

2. Zhu C, Fan L-S. Dense-Phase Fluidized Beds. In: Zhu C, Fan L-S, eds. Principles of Gas-Solid Flows . Cambridge: Cambridge University Press; 1998:371-420.

3. Lim KS, Zhu JX, Grace JR. Hydrodynamics of gas-solid fluidization. International Journal of Multiphase Flow.1995/12/01/ 1995;21:141-193.

4. Bi HT, Grace JR. Flow regime diagrams for gas-solid fluidization and upward transport. International Journal of Multiphase Flow. 1995/11/01/ 1995;21(6):1229-1236.

5. Smolders K, Baeyens J. Gas fluidized beds operating at high velocities: a critical review of occurring regimes. Powder Technology. 2001/09/24/ 2001;119(2):269-291.

6. Kunii D, Levenspiel O. Fluidization engineering (Chapter 7: Turbulent fluidization). ButterworthHeinemann series in chemical engineering . 2nd ed. Boston: Butterworth-Heinemann,; 1991.

7. Bi HT, Ellis N, Abba IA, Grace JR. A state-of-the-art review of gas-solid turbulent fluidization. Chemical Engineering Science. 2000/11/01/2000;55(21):4789-4825.

8. Mostoufi N, Chaouki J. Flow structure of the solids in gas-solid fluidized beds. Chemical Engineering Science.2004/10/01/2004;59(20):4217-4227.

9. Zhu C, Fan L-S. Circulating Fluidized Beds. In: Zhu C, Fan L-S, eds. Principles of Gas-Solid Flows . Cambridge: Cambridge University Press; 1998:421-460.

10. Jaiboon O-a, Chalermsinsuwan B, Mekasut L, Piumsomboon P. Effect of flow pattern on power spectral density of pressure fluctuation in various fluidization regimes. Powder Technology. 2013/01/01/ 2013;233:215-226.

11. Bai D, Issangya AS, Grace JR. Characteristics of Gas-Fluidized Beds in Different Flow Regimes. Industrial \& Engineering Chemistry Research. 1999/03/01 1999;38(3):803-811.

12. Sun G, Grace JR. Effect of particle size distribution in different fluidization regimes. AIChE Journal. 1992/05/01 1992;38(5):716-722. 
13. Horio M, Ishii H, Nishimuro M. On the nature of turbulent and fast fluidized beds. Powder Technology. 1992/06/01/ 1992;70(3):229-236.

14. Chew JW, Hays R, Findlay JG, et al. Species segregation of binary mixtures and a continuous size distribution of Group B particles in riser flow. Chemical Engineering Science. 2011/10/15/ 2011;66(20):45954604 .

15. Chew JW, Hays R, Findlay JG, et al. Impact of material property and operating conditions on mass flux profiles of monodisperse and polydisperse Group B particles in a CFB riser. Powder Technology. 2011/11/25/ 2011;214(1):89-98.

16. Chew JW, Hays R, Findlay JG, et al. Cluster characteristics of Geldart group B particles in a pilot-scale CFB riser. II. Polydisperse systems. Chemical Engineering Science. 2012/01/22/ 2012;68(1):82-93.

17. Chew JW, Hays R, Findlay JG, et al. Cluster characteristics of Geldart Group B particles in a pilot-scale CFB riser. I. Monodisperse systems. Chemical Engineering Science. 2012/01/22/ 2012;68(1):72-81.

18. Anantharaman A, Karri SBR, Findlay JG, Hrenya CM, Cocco RA, Chew JW. Interpreting Differential Pressure Signals for Particle Properties and Operating Conditions in a Pilot-Scale Circulating Fluidized Bed Riser. Industrial $\mathcal{E}$ Engineering Chemistry Research. 2016/08/10 2016;55(31):8659-8670.

19. Anantharaman A, Issangya A, Karri SBR, et al. Annulus flow behavior of Geldart Group B particles in a pilot-scale CFB riser.Powder Technology. 2017/01/01/ 2017;305:816-828.

20. Chew JW, Parker DM, Cocco RA, Hrenya CM. Cluster characteristics of continuous size distributions and binary mixtures of Group B particles in dilute riser flow. Chemical Engineering Journal. 2011/12/15/ 2011;178:348-358.

21. Chew JW, Parker DM, Hrenya CM. Elutriation and Species Segregation Characteristics of Polydisperse Mixtures of Group B Particles in a dilute CFB Riser. AIChE Journal. 2013/01/01 2013;59(1):84-95.

22. Breiman L. Random Forests. Machine Learning.2001/10/01 2001;45(1):5-32.

23. Kohonen T. The self-organizing map. Proceedings of the IEEE. 1990;78(9):1464-1480.

24. Vesanto J, Alhoniemi E. Clustering of the self-organizing map. IEEE Transactions on Neural Networks. 2000;11(3):586-600.

25. Chew JW, Cocco RA. Application of machine learning methods to understand and predict circulating fluidized bed riser flow characteristics. Chemical Engineering Science. 2020/05/18/ 2020;217:115503.

26. Patel AM, Cocco RA, Chew JW. Key Influence of Clusters in a Circulating Fluidized Bed Riser. submitted, Chemical Engineering Journal. 2020.

27. Chew JW, Cocco RA. Do particle-related parameters influence circulating fluidized bed (CFB) riser flux and elutriation? Chemical Engineering Science. 2020;227:115935.

28. Kim SW, Kirbas G, Bi H, Jim Lim C, Grace JR. Flow behavior and regime transition in a high-density circulating fluidized bed riser. Chemical Engineering Science. 2004/09/01/2004;59(18):3955-3963.

29. Grace JR, Issangya AS, Bai D, Bi H, Zhu J. Situating the high-density circulating fluidized bed. AIChE Journal.1999;45(10):2108-2116.

30. Chew JW, Cahyadi A, Hrenya CM, Karri R, Cocco RA. Review of entrainment correlations in gas-solid fluidization. Chemical Engineering Journal. 2015/01/15/ 2015;260:152-171.

31. Rahaman MF, Sarhan AR, Naser J. Kinetic theory for multi-particulate flow: Description of granular flow with rotary movement of particles. Powder Technology. 2020/01/15/ 2020;360:780-788.

32. Songprawat S, Gidaspow D. Multiphase flow with unequal granular temperatures. Chemical Engineering Science. 2010/02/01/ 2010;65(3):1134-1143. 
33. Das M, Meikap BC, Saha RK. Characteristics of axial and radial segregation of single and mixed particle system based on terminal settling velocity in the riser of a circulating fluidized bed.Chemical Engineering Journal. 2008/12/01/ 2008;145(1):32-43.

34. Du M, Wang S. Investigation of the segregation of a binary particle mixture in a square circulating fluidized bed with air staging.Particuology. 2019/12/01/ 2019;47:70-76.

35. Zhang $\mathrm{H}, \mathrm{Lu} \mathrm{Y}$. A computational particle fluid-dynamics simulation of hydrodynamics in a threedimensional full-loop circulating fluidized bed: Effects of particle-size distribution.Particuology. 2020/04/01/ 2020;49:134-145.

36. Mathiesen V, Solberg T, Hjertager BH. An experimental and computational study of multiphase flow behavior in a circulating fluidized bed. International Journal of Multiphase Flow.2000/03/01/2000;26(3):387419.

37. Chew JW, Wolz JR, Hrenya CM. Axial segregation in bubbling gas-fluidized beds with Gaussian and lognormal distributions of Geldart Group B particles. AIChE Journal. 2010/12/01 2010;56(12):3049-3061.

38. Gauthier D, Zerguerras S, Flamant G. Influence of the particle size distribution of powders on the velocities of minimum and complete fluidization. Chemical Engineering Journal. 1999/07/19/ 1999;74(3):181-196.

39. Lin C-L, Wey M-Y, You S-D. The effect of particle size distribution on minimum fluidization velocity at high temperature.Powder Technology. 2002/08/12/ 2002;126(3):297-301. 